\title{
Development of Intelligent Transport System for Detection System Location Traffic Accidents
}

\author{
Marson James Budiman \\ Department of Computer \\ Engineering, \\ Manado State Polytechnic
}

\author{
Stephy Walukow \\ Department of Computer \\ Engineering, \\ Manado State Polytechnic
}

\author{
Herry Makapedua \\ Department of Computer \\ Engineering, \\ Manado State Polytechnic
}

\begin{abstract}
Accidents often occur in large cities, such as the incidence of a hit and run or accidents medium and heavy not directly detectable, such as the location and type of vehicle by a traffic officer so that the handling of the case of an accident can be long and with such conditions it can be ascertained there will be traffic jams that disrupted travel comfort. This research aims to design a model of location detection system Google map -based traffic accidents in the city of Manado, a system built will integrate location information and vehicle data from traffic accidents through road location map. The system uses Google map technology to display the location of a traffic accident, it is the model that is used in application development interface of a GPS sensor device to a computer that is done on the media side of the management system, and the user side. The result of the application of the system built is a GPS signal when the accident occurred on a motor vehicle would send a signal to a server and displaying the location of the accident. The results of the draft provide an output display on the user side and is expected as a guide for the parties concerned to deal quickly, as well as for road users to be able to choose an alternative path in the event of accidents resulting in traffic congestion, so that the level of congestion can be reduced.
\end{abstract}

\section{Keywords}

Traffic accident, point coordinates, Information Systems

\section{INTRODUCTION}

The problem of congestion is the most common in urban areas. The fact of urban happened imbalance between the growth rate of road on one side with the growth rate of the vehicle on the other hand, where the growth path is much smaller than the growth rate of the vehicle, the data Revenue Service of North Sulawesi until 2012, in North Sulawesi increased by 9000 to 34,000 four-wheeled vehicles and twowheelers. According to Kadishub Manado City Yohanis B. Waworuntu the data revealed that the number of public transport fleets active in Manado City is as much as 4,667 vehicles, with passenger numbers average of 150 passengers / day, and the load factor of $60 \%$. With such conditions, you can bet there will be traffic jams, travel comfort is compromised, the boredom of travel, travel fatigue, loss of time and materials, all of which lead toward violations and traffic accidents. Based on data from the North Sulawesi Police Ditlantas, presentation accident at the age of 15-25 years reached 77.7 percent for the year 2014 .

\section{METHODOLOGY}

\subsection{Phase early diagnosis}

At this stage will be to identify existing problems, in order to be able to anticipate all the problems associated with going to a new system. The problems identified are How to monitor traffic congestion due to the condition of a traffic accident, at a point different locations .

\subsubsection{Transport}

Understanding transportation by D.Setijowarno \& Hadihardja is moving or transporting from one place to another [5], [8]. According to HA Abbas Salim, the definition of transportation is the movement of goods or passengers from one location to another, with a product-driven or moved to a location that is desired or needed [7]. Understanding according to Warpani transportation is transportation facilities and infrastructure as well as activities that serve as a tool to facilitate the achievement of that location [14]. According to Mokhamat AnsorTransportasi street organized with the aim to realize the traffic and road transport with a safe, secure, fast, orderly, convenient and efficient, able to integrate other modes of transport, reaches all corners of the land area, to support equity, growth and stability as a driving force , driving and supporting national development at a cost affordable by the community [15].

\subsubsection{Traffic Light}

Every intersection should be installed an integrated system of traffic control (traffic control area) so that each of the intersections is included in the relevant area should be controlled by means of signaling traffic. (source: Towards Traffic and Road Transport are tongue [1].

Accidents often occur in large cities, such as hit-and-run incident or accident moderate or severe, are not directly detectable in the form of the location and type of vehicle by a traffic officer, so that the handling of the case of an accident can be prolonged. Based on these events, will be built system with GPS technology installed on motor vehicles, in case of accident in this case the impact on the body of the vehicle, the GPS signal would work sends a signal to the device server computer technology media google maps will inform the crash site and the type of vehicle when the accident occurred. The system is expected to provide information quickly to related parties and the public road users about the areas that are jammed due to the condition of a traffic accident when traveling, this condition is very important in improving the performance of traffic management such as traffic congestion and traffic accident information.

\subsection{The planning stage}

At this stage drafting system. The research plan as follows: starting from a field survey, accident-prone road conditions according to the research objectives that have been set. In this system will be made on the information system maps showing the paths that indicate the density of vehicles due to a traffic accident conditions. With the design of the system as in Figure 1. 


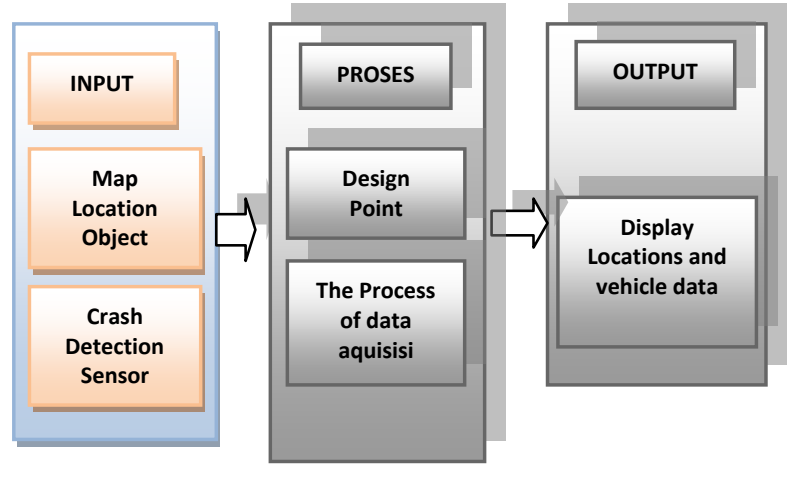

Fig. 1 system design diagram

network connection every parameter input Figure 1 starting from the crash detection sensor will give a signal to the PC server and map the location of the object, the signals are processed into the data path information on the location map on the client side in the form of accident location data and vehicle data.

\subsection{The implementation stage}

At this stage of development of the system architecture is based on the results of diagnostic analysis of system requirements, as well as testing the system by measuring the speed of user access. The system will inform the location and vehicle data in case of accidents with the color of the form of the circles and long lines are displayed on the coordinates point location map.

\section{RESULTS AND DISCUSSION}

In the process of interface system there are several options that support business process system. Briefly this process are as follows: Process design point coordinates (Admin), Process monitoring (User / Client), Process report (Admin) The Admin will handle the design process, and the Report, while the User or Client will relate to process information systems As the stages are done in building applications, namely:

\subsection{The design process coordinates point}

The stages are done in determining the coordinates of the google map to pinpoint the location of an accident traffic, as follows :

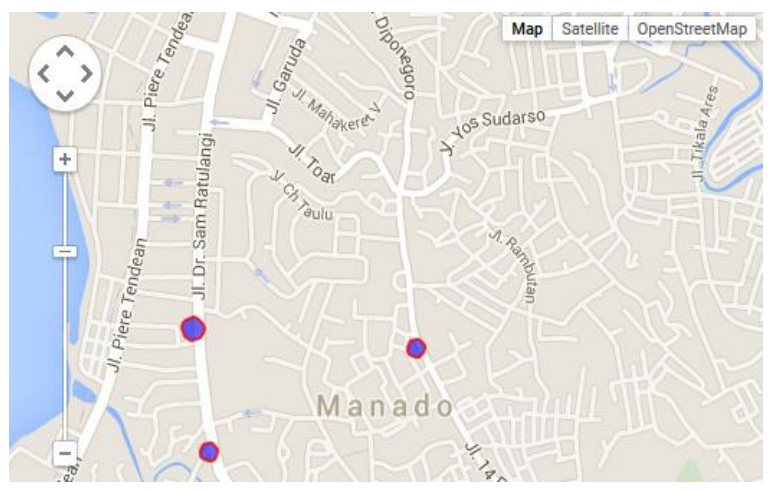

Fig. 2 Use of API Tool coordinates on a google map

using Google MapsApi Fig 2. Tool V3 Google Maps provides an API to get the javascript code and point coordinates. Gbr2. displays the map coordinates of a location is used to display the location map of the study area in units of Latitude and Longitude coordinates. Google Map API is an application interface that can be accessed via javascript that Google Maps can be displayed on a web page that is being built.

\subsection{Response Testing System}

Testing the response system includes testing GPS sensor detected vehicle accident to a computer device that receives GPS signals and then displayed on the media google map, simulated by activating the GPS signal which will give a signal to the server.

Table 1. Table Position Tool Test Result GPS and Receiver

\begin{tabular}{|c|c|c|c|c|}
\hline No & Location & $\begin{array}{c}\text { GPS } \\
\text { coordinates } \\
\text { Data Tools } \\
\text { SMS } \\
\end{array}$ & $\begin{array}{c}\text { coordinates } \\
\text { Google } \\
\text { Maps view }\end{array}$ & $\begin{array}{l}\text { WITA } \\
\text { Time }\end{array}$ \\
\hline 1 & Jl.AA.Maramis & $\begin{array}{c}1.292032, \\
124.512679\end{array}$ & $\begin{array}{c}1.292042, \\
124.511579\end{array}$ & 08.00 \\
\hline 2 & Jl.Yos Sudarso & $\begin{array}{c}1.292452, \\
124.522468\end{array}$ & $\begin{array}{c}1.292354, \\
124.512468\end{array}$ & 10.00 \\
\hline 3 & $\begin{array}{c}\text { Jl.Re } \\
\text { Martadinata }\end{array}$ & $\begin{array}{c}1.292862, \\
124.512331\end{array}$ & $\begin{array}{c}1.291961, \\
124.511521\end{array}$ & 12.00 \\
\hline 4 & J1.Balai Kota & $\begin{array}{c}1.295334, \\
124.514461\end{array}$ & $\begin{array}{c}1.285336 \\
124.505465\end{array}$ & 15.00 \\
\hline 5 & Jl.14 Februari & $\begin{array}{c}1.295258, \\
124.515151\end{array}$ & $\begin{array}{c}1.285258, \\
124.505180\end{array}$ & 17.00 \\
\hline 6 & Jl.Toar & $\begin{array}{c}1.295112, \\
124.515021\end{array}$ & $\begin{array}{c}1.285214, \\
124.505087\end{array}$ & 20.00 \\
\hline 7 & $\begin{array}{c}\text { Jl.Sam } \\
\text { Ratulangi }\end{array}$ & $\begin{array}{c}1.292270, \\
124.514621\end{array}$ & $\begin{array}{c}1.285260, \\
124.504930\end{array}$ & 21.00 \\
\hline 8 & $\begin{array}{l}\text { Jl.Piere } \\
\text { Tendean }\end{array}$ & $\begin{array}{c}1.295421, \\
124.514911\end{array}$ & $\begin{array}{c}1.285229, \\
124.504912\end{array}$ & 23.00 \\
\hline 9 & Jl.Ahmad Yani & $\begin{array}{c}1.29355, \\
124.517352\end{array}$ & $\begin{array}{c}1.29425, \\
124.504357\end{array}$ & 02.00 \\
\hline
\end{tabular}

Testing is done by detecting both devices are GPS sensor device with a display coordinate point on the location of the accident and the display coordinates of the user's side is a map of the location on a google map. From Table 1 were obtained an average error is relatively small. GPS coordinates of the point value received by the PC via the GSM network in the form of point coordinates short message service, and short message service data is subsequently converted to display the location on a google map.

Table 2. Table response sensor test results by type of conflict

\begin{tabular}{|c|c|l|}
\hline $\begin{array}{c}\text { Total } \\
\text { User }\end{array}$ & $\begin{array}{l}\text { Response Tool GPS } \\
\text { (seconds) }\end{array}$ & Conflict type \\
\hline \multirow{3}{*}{1} & 2.54 & Mild \\
\cline { 2 - 3 } & 1.65 & Medium \\
\cline { 2 - 3 } & 1.03 & Light \\
\hline \multirow{2}{*}{2} & 2.58 & Mild \\
\cline { 2 - 3 } & 1.57 & Medium \\
\hline
\end{tabular}




\begin{tabular}{|l|c|l|}
\hline \multirow{3}{*}{3} & 1.01 & Light \\
\hline \multirow{3}{*}{3} & 2.60 & Mild \\
\cline { 2 - 3 } & 1.56 & Medium \\
\cline { 2 - 3 } & 1.04 & Light \\
\hline
\end{tabular}

Testing types of collisions taken three conditions, namely conflict of mild, moderate, severe simulated by providing vibration response on GPS equipment with an average response 2:57 seconds on the type of collision when the light sensor detects vibration, 1.59 seconds for the type of collision was, and 1.02 seconds for a heavy impact.

\subsection{User Response Testing}

Testing is one of the quality systems that of the most important for quality assurance. application system that has been tested is a new challenge for quality assurance and testing. The experiments were performed by running the client applications and data. Applications on the client turned on gradually the numbers to determine the rate of data as the number of users online. The level of speed is calculated by calculating the time from delivery to receipt of data. The results are shown in Table 3 .

Table 3. Table Response time test result with speed networking and upload 79Kbps, $250 \mathrm{Kbps}$

\begin{tabular}{|c|c|c|c|}
\hline Total User & $\begin{array}{c}\text { Response } \\
\text { Time } \\
\text { (seconds)/ } \\
\text { 250Kbps }\end{array}$ & $\begin{array}{c}\text { Response } \\
\text { Time } \\
\text { (seconds)/ } \\
\text { 79Kbps }\end{array}$ & $\begin{array}{l}\text { Response } \\
\text { Point } \\
\text { Coordinates } \\
\text { Manado city }\end{array}$ \\
\hline 1 & 1.57 & 2.34 & $\begin{array}{c}1.477543 \\
124.845447\end{array}$ \\
\hline 2 & 1.62 & 2.35 & $\begin{array}{c}1.477543, \\
124.845447\end{array}$ \\
\hline 3 & 1.61 & 2.33 & $\begin{array}{c}1.477543, \\
124.845447\end{array}$ \\
\hline 4 & 1.58 & 2.35 & $\begin{array}{c}1.477543, \\
124.845447 \\
\end{array}$ \\
\hline 5 & 1.59 & 2.35 & $\begin{array}{c}1.477543, \\
124.845447\end{array}$ \\
\hline 6 & 1.62 & 2.34 & $\begin{array}{c}1.477543, \\
124.845447\end{array}$ \\
\hline 7 & 1.61 & 2.40 & $\begin{array}{c}1.477543, \\
124.845447\end{array}$ \\
\hline 8 & 1.62 & 2.36 & $\begin{array}{c}1.477543, \\
124.845447\end{array}$ \\
\hline 9 & 1.62 & 2.34 & $\begin{array}{c}1.477543, \\
124.845447 \\
\end{array}$ \\
\hline
\end{tabular}

\subsection{Implements Interface}

The information system is the system provides an indication of any signal detected by the map location of the object with the coordinates of which is shown in Figure 3.

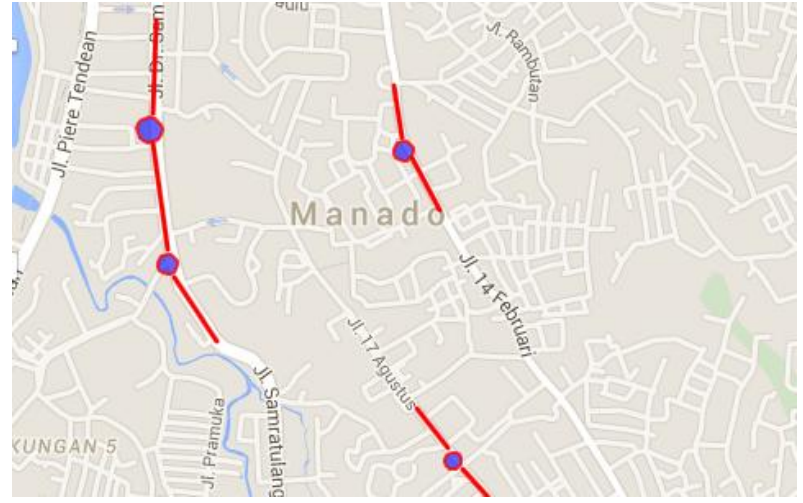

Fig 3. Display current coordinates of observed accidents.

\section{CONCLUSIONS}

Based on test results showed that the application of the system of traffic information on the accident scene and vehicle data that accidents can be displayed by using the media google maps based on sensor input is detected in each vehicle. Information on each road traffic accident in progress can be obtained in real time 24 hours in the area of point coordinates are specified. Unity made a computerized system with GPS devices installed in motor vehicles, resulting in the data being displayed on google maps. Information Point location coordinates of the incident with a view Polyline and Circle colored on the road. In developing the system needs to be added to the system to detect the type of collision accident, the condition of the vehicle damage, so that police officers can evaluate and compare data recording apparatus and data witness testimony.

\section{ACKNOWLEDGMENTS}

Thanks to the Ministry of Research and Technology of Technology and Higher Education, which has funded this research with competitive grants program in 2015 , so as to do research and work well.

\section{REFERENCES}

[1] Abu Bakr Iskandar.DKK. 1995. Towards Traffic and Road Transport are tongue, Jakarta. Directorate General of Land Transportation.

[2] Aries Setijadi, Road Traffic Congestion Study Kaligawe City Semarang, Semarang Diponigoro University thesis

[3] Afrias Sarotama, Mohammad M. Sarinato, Juniar Ganis, Development of Interactive Electronic Map, proceedings KOMMIT 2002

[4] Bob D. Sinulingga, Urban Development and Regional Local Review,Publisher Pustaka Sinar Harapan, 1999.

[5] D.Setijowarno \& RB Frazila, Introduction to Transportation Systems, Publisher Catholic University of Semarang Soegijapranata 2001

[6] Eko Budihardjo, the City Spatial Urban, Publisher Alumni, 1997

[7] HA Abbas Salim, Transportation Management, Publisher PT. King Grafindo Persada Jakarta, 1993. [8] Hadihardja, Joetata. DKK. 1997.Sistem Transportation. Jakarta. Publisher Guna Darma.

[8] Sugiyono, "Understanding Qualitative Research", Bandung, Alfabeta 2012. 
[9] W. Gulo, Research Methodology, Grasindo Publishers, 2002.

[10] Ofyar Z. Tamin, planning and transport modeling, Publisher ITB Bandung, 2000.

[11] james Marson Budiman, Zahir Zahinuddin, Amil Ahman Ilham, Monitoring and Control Systems Urban traffic .Jurnal Hasanuddin University, 2012.
[12] Andy AM Malik, identification of traffic congestion in the city center Paal2 and Manado. Sam Ratulangi University in Manado, 2011.

[13] Warpani.S, plainly traffic management and road transportation, ITB, Bandung, 2002.

[14] Mokhamat Ansori, Mohammad Kanzunnudin, Application Traffic Management in the field of transportation, STIEPARI, Semarang, 2000. 